\title{
Organization of Training HR-Specialists of Coal Mining Enterprises
}

\author{
Valeriy Bobrikov ${ }^{1}$, Nikita Ravochkin ${ }^{2 *}$, Marina Gorbacheva ${ }^{1}$, and Ammar Jamous ${ }^{3}$ \\ ${ }^{1}$ T.F. Gorbachev Kuzbass State Technical University, 650000, Kemerovo, Russian Federation \\ ${ }^{2}$ Kemerovo State Agricultural Institute, 650056, Kemerovo, Russian Federation \\ ${ }^{3}$ Damascus University, Damasc, Syrian Arab Republic
}

\begin{abstract}
Based on trends in the socio-economic sphere of public life, in particular the education sector, and taking into account the specifics of the Russian coal mining industry enterprises, in this article the authors address the problem of the organization of training of the coal mining industry HR specialists. The role of these workers in coal mining enterprises is shown in the study. The impact of globalization, which has led to the obsolescence of knowledge and doesn't guarantee the constancy of the work being done, even within the same industry, is noted. Views on investment in the development of human resources of an enterprise are analyzed. Based on the use of their own methods, the authors give a vision of the profile of an HR specialist of coal mining enterprises. A critical analysis of the organization of training of HR specialists, depending on customer requirements, is presented. In conclusion, the work gives practical recommendations on the organization of HR specialists training.
\end{abstract}

\section{Introduction}

The current acceleration of social dynamics is conjugated with a high degree of uncertainty, which also leaves its mark on the development of a profession or a specialty. The principle of "once and for all" is not possible even within the same industry. So in the coal mining industry we are considering, there is a sharp reduction in the life cycle of specialties with a simultaneous increase in the number of possible "future professions" and the more profound specializing. It follows that a number of industry specialties become obsolete, retiring from the labor market at a certain stage, while others, on the contrary, appear due to the development of new technologies. It seems pessimistic that their appearance and updating often happens spontaneously, and the industry manpower does not undergo the necessary training. Knowledge and skills, whose life cycle is shortened by analogy, are in permanent renewal and improvement. It is obvious that the life cycle of educational training programs is also shortening, but on the other hand the need for new approaches to the organization of training is sharply increasing. All this make relevant the issue of the harmonious organization of educational paths taking into account the needs of the real sector.

${ }^{*}$ Corresponding author: nickravochkin@mail.ru 
It is also substantive that the coal mining industry is one of the important sectors of the Russian energy economy. The competitive advantages of the Russian coal mining industry are aimed at ensuring the security of energy supply of Russia, which consists mainly in the presence of huge coal reserves, as well as the considerable experience in its production and subsequent use. A significant part in the successful development of the industry is assigned to the "Program for the Development of the Coal Mining Industry in Russia for the Period Until 2030", according to which the improvement of the system of professional training of the coal mining industry HR specialists is a priority among the planned activities [1]. This implies significant progress in the qualitative aspects of the coal mining industry HR policy and a new level of competitiveness. Reasoning in this context, let us say that the primary condition for the efficiency is the modernization of the State education policy, directed according to the principle of "Business - Education - Science". The latter means that personnel training in the field of coal mining industry should be as congruent as possible to the modern requirements of not only the economic situation, but also use advanced scientific results.

\section{Theory}

In connection with the emergence of a new type of society from the middle of the last century, the theory of human capital has become dominant, and the educational resources of an organization have become one of the leading competitive advantages. At the same time, it is essential to recall their regular updating according to current needs. The authors believe that the capitalization of the company's personnel knowledge as well as the continuity of its gaining in the course of practical activities are responsibilities of HR specialists, on the level of education of which the future income growth depends. Taking into account the market economy, in terms of economic efficiency our thesis means that high-quality training of this target audience will lead to indirect investments in staff training and development, involving a greater variety of application of the knowledge gained [10;11].

In accordance with the logic of the study, consider the macro segment of coal mining enterprises. It should be noted that the characteristic feature of modern coal mining enterprises is the permanently increasing role of the human factor, which is nowadays directly related to the emergence of specific requirements to interpersonal, engineering, technological and conceptual components of personnel competence, as well as the increasing role of scientific and technological progress, labor intellectualization and innovativeness. All this moulds a new view on human resources of these enterprises. Additionally, it is noteworthy that, at present, most enterprises of the industry can no longer rely only on attracting investments, leasing experts or conducting marketing research to achieve performance indicators and increase competitiveness. The efficiency of an enterprise depends to a large extent on the attitude of owners and management to their personnel and a comprehensible structure of interaction with subordinates [2;5].

Enterprises traditionally invest in their staff training and development. However, it would not be superfluous to refer to the history of this issue. Investments in personnel training and development in enterprises are associated with the Industrial Revolution and the genesis of management at the turn of the XIX-XX centuries. Subsequent development was accompanied by corresponding transformations, mainly in the areas of economics and technologies. If previously employees were trained on their own, now as a "channel" of personnel training in the interests of owners and managers of enterprises are considered as a kind of "external providers" of educational services [6].

In turn, D. Ulrich, M. Losey \& S. Meisinger note that training and development of personnel for each enterprise is an essential element of productive investment. In addition, encouraging employees' training, the company offers them the opportunity to increase their 
attainment level. This becomes relevant in the conditions of a shortage of highly qualified personnel, the increasing competition that requires the efficient use of labor resources, the increasing labor cost, the prevalence of technical features and changes associated with scientific and technological progress and the introduction of information technology, an increase in production and sales, and the possibilities to build employees' capabilities and the strengthening role of corporate accountability [12].

A. Krausert interprets personnel training as the best way to quickly and efficiently train personnel for the goals and needs of an enterprise with a focus on specific technologies and the capabilities that have been built. This researcher also notes that time and money costs are minimized when solving new problems [9]. This is really necessary in view of the fact that, as practice shows, personnel are less and less display an excess of knowledge and, as a rule, in close connection with work, but not in accordance with the specialty acquired earlier. M. Černe, S. Batistič \& R. Kenda emphasize modern conditions that enhance the competitive advantages of the enterprise personnel capabilities, the efficiency of which is determined through training. They do not specify what kind of training - individual, group or collective - seems to be the most advantageous [7]. They offer us ourselves to place accents depending, quite likely, on the size of an enterprise and trainees' profiles. However, it is necessary to once again recall the growing role of knowledge economy, which, as is well known, implies an increase in the level of competence, first of all, of people engaged in intellectual works, i.e. management staff. From here we will point out the need to introduce advanced foreign experience and methods for personnel training. Here we cannot fully agree with the authors, since there is no consideration of Russian realities and industry specificities. Foreign experience in the organization of personnel training in the USA, Japan and Europe is highlighted in the scientific works of W.F. Cascio \& J.W. Boudreau as well as M. Dickmann, C. Brewster C. \& P. Sparrow [4; 8]. For example, in American enterprises, sufficient importance is attached to systematic training and professional development of workers. Colossal resources (financial, material, temporary, and human) are spent on development and training of personnel, since they correlate with profit. In the United States, staff investment tends to grow steadily. In Japanese companies personnel training is guided by the principle of "human capabilities", i.e. emphasizing the real capabilities of an employee to show and develop his or her abilities. When training staff, the Japanese refer to the following postulate: "the knowledge of the individual employee and the knowledge of the entire organization". Unlike the United States and Japan, where personnel is commonly trained in educational organizations, in Europe large corporations establish their own training centers and universities where their personnel is trained. It should be noted that personnel training abroad is carried out within the framework of the system, which involves a combination of theoretical and practical training cycles $[4 ; 8]$.

In our opinion, in today's market conditions, enterprises should regularly invest in development and education of employees. This is mainly due to such tendencies that nowadays workers, as well as those who provide their professional training, face a set of fundamentally new tasks arising from the needs of enterprises to adapt to the market, modernizing and re-profiling industries, which were the result of employment restructuring and the changes in labor quality requirements. We pay attention to the consideration of the individual characteristics of the trained personnel profile. So, taking into account the different age of staff and various levels of their education and experience in their specialties and a range of individual characteristics, it is necessary to refer to these indicators. When investing in staff training, in terms of the organization of the process we are considering these variables determine:

1. The scale of education and the factors affecting it;

2. Forms of implementation of educational activities to achieve the desired result at optimal costs; 


\section{A rational combination of old and new professions.}

\section{Results and discussion}

The social dynamics of modern transformations necessitates the training of HR specialists for the development, for example, of analytical skills, which are so necessary for making and implementing non-standard solutions in order to increase the competitiveness of an enterprise. In this, we agree that to train a competent specialist who meets the requirements of innovative economy is a priority of the system of continuing education in the field of HR management. The HR specialist profession requires continuous (self)-development and participation in learning processes, which will help to professionally improve and develop the required professional skills. Turning to HR specialists in the coal mining industry, we find with pessimism that they do not always have a specialized basic education, which makes them incompetent in various areas of current practice.

Firstly, as the analysis of educational programs of higher educational institutions of the relevant mining profile shows, there are no programs of human resource management for the coal mining industry (there is an abstract "human resource management at an enterprise" without specifying a profile. The authors propose a project of the organization of training according to the program: "Mining/construction enterprise HR management"). Secondly, HR specialist training is impossible without knowledge of the specifics of sectoral processes and the relevant practice. Third, the ex-post state-of-the-art shows that the majority of HR specialists employed in the coal mining industry are former engineers who have their own vision of personnel management problems, backed up by previous experience, but not by management paradigms.

The modern world requires profiling of an enterprise human resources training. The coal mining industry is no exception and increases the demands for competent HR specialists, whose training profile is directly related to it. Also, growing demands, as the experience of coal mining enterprises shows, are associated with an increase in staff of departments that are directly involved in HR matters (these include: personnel training and development center, personnel management service, HR department, etc.).

Focusing not only on these opinions, but also on our own methodology, developed in concert with the chiefs of the Kuzbass coal mining enterprises and HR specialists as trainees, we can construct our own profile of an HR specialist of the coal mining industry. The core of the methodology developed by us is the systematization of the main criteria that fully meet the expected requirements of not only managers and owners of enterprises, but also HR specialists themselves, who observe their colleagues from outside perspective:

- focus on the rapid achievement of the desired result while following long-term goals. The ability to form an internal vision of the planned work of the staff, while applying maximum effort and resources to quickly achieve the specified plans;

- attaching a high value to self-fulfillment and the content of tasks to be solved relying on own knowledge and experience. Correct and competent self-esteem ensures the correct progress towards the goal and satisfaction of needs. In cases where a person has the necessary capabilities and feels that he/she is in fact a highly qualified specialist, which executes meaningful tasks guided by experience, this will fully contribute to an effective personnel policy in the coal mining industry;

- desire for creativity: innovative thinking that guarantees an individual approach to each employee;

- ability to risks;

- ability to argue and support personal point of view;

- desire for a business communication style, a comfortable psychological climate, a structured schedule of activities; a qualified specialist should have the well-bred speech 
skills, command a copious vocabulary of professional terms, and be able to conduct business negotiations. Also an important factor is the ability to organize own work schedule, distribute primary and secondary tasks that would contribute to the efficient organization of own activities in the context of the entire enterprise;

- strong motivation to the content of the work, moderate one to material reward. Since the coal mining industry is a collective work activity, the success of which depends on a team, an HR specialist should be interested in the final result of the work of the entire team, and not only in his own material security;

- having own ideas about his or her career and place in society, self-sufficiency and the ability to adequately assess own strengths while unlocking his or her own potential in the required area, will no doubt help to transfer this quality to other employees. It is important that every worker employed in a coal mining enterprise has its own place in the process of its operation, which would contribute to the development of the industry. Therefore, it is important to correctly assess own prospects, including in the process of climbing the career ladder.

We earlier noted that the organization of training of HR specialists should take place in accordance with the "Program for the Development of the Coal Mining Industry in Russia for the Period Until 2030". Considering the fact that this educational process must be efficient and structured, careful planning of the educational space elements is needed, which is carried out at the design stage. The educational program itself, as well as the educational space, can have different scales, since it eliminates the gaps of incompetence in a particular practical area of HR specialists or has a focus on their participation in the subsequent professional development of enterprise personnel to achieve specific economic goals. It is no coincidence, because at coal mining industry enterprises there are many factors contributing to the achievement of the professional development goals set by management for a certain category of personnel. The content of educational programs must be given, above all, an applied focus, which in one way or another will serve the interests of increasing the efficiency and effectiveness of social labor. The organization of training of HR specialists of coal mining enterprises should also not go against the concept of the development of education, which ensures their substantial updating [3].

\section{Conclusions}

Thus, our study on the organization of training of HR specialists allows concluding that the main and urgent problem is a continuous and is in the process of organizing the interaction of customers and consumers with educational institutions of continuing professional education. Inaccurate understanding of goals and objectives leads to the fact that, as domestic practice shows, the acquisition of competences by trainees is not controlled, they are overloaded with theoretical training, and training is conducted not by practicing professionals, but by academic theorists. Also in practice, the subsequent assessment of the efficiency of the educational programs mastered by the trainees suffers.

We agree with those researchers who believe that the problems of the coal mining industry, in particular, measures to increase its productivity and profitability, today are truly a "sore subject." However, we will not consider industry threats and opportunities for its development, noting only that this period, associated with the rapid pace of updating knowledge and indicating that "the coal mining industry has overcome the negative trends of the global crisis, and the systematic solution of the main problems will allow it to be brought to a new level of development» naturally leads to the formulation of the problem of the need to train (highly)-qualified personnel.

It is the level of attainment of HR specialists of coal mining enterprises that will contribute to solving the personnel problems of the industry, since vocational guidance of 
students and graduates, increasing the prestige of work in the coal mining industry (HR branding), general competitiveness increase through ensuring the efficiency of internal staff training programs depend on their competence. The modern labor market also requires new personnel, for the efficient involvement of which it is necessary to increase the competence of those who manage them, especially since they form the level of reliability of personnel consisting of qualification, psychophysical state and motivation.

As specific recommendations on the organization of training of HR specialists of the coal mining industry in various educational programs, it is first necessary to specify their profiles and increase the coverage of the target audience; organize advanced training; on a scientific basis to develop modern approaches to internal staff training, to develop mechanisms for assessing the efficiency of training; in the process of learning, to make the HR specialists themselves not only to acquire, but also the subsequently use the innovative pedagogical technologies and actively introduce multimedia when working with staff, in order to avoid their stereotypical perception of the coaches conducting training as a socalled "talking head".

\section{References}

1. The Government of the Russian Federation from June 21, 2014 N 1099-r "On the Program for the Development of the Coal Industry of the Russian Federation for the Period up to 2030» (Russian Newspaper, Moscow, 2014)

2. J. Beardwell, T. Thompson, Human Resource Management: A Contemporary Approach. Pearson (Friedman Pub., London, 2017)

3. V. Bobrikov, N. Ravochkin, V. Shchennikov, E3S Web Conf., 41, 04014 (2018)

4. W.F. Cascio, J.W. Boudreau, Journal of World Business, 51:1, 103 (2016)

5. R. Christensen, AMACOM. (2006)

6. D. J. Cohen, HR past, present and future: A call for consistent practices and a focus on competencies Human Resource Management Review, 25:2, 205 (2015)

7. M. Černe, S. Batistič, R. Kenda, Human Resource Management Review., 28:3, 271 (2018)

8. M. Dickmann, C. Brewster, P. Sparrow, International Human Resource Management: A European perspective (Routledge, New York, 2008)

9. A. Krausert, Human Resource Management Review, 27:3, 442 (2017)

10. L.H. Nishii, R.M. Paluch, HR systems. Human Resource Management Review, 28:3, 319 (2018)

11. J.J. Phillips, Accountability in human resource management: Techniques for Evaluating the Human Resource Function and Measuring Its Bottom-line Contribution. Butterworth-Heinemann (Routledge, New York, 2007)

12. D. Ulrich, M. Losey, S. Meisinger, Future of Human Resource Management: 64 Thought Leaders Explore the Critical HR Issues of Today and Tomorrow (Wiley, New York, 2005) 